\title{
Cardiac Affection in Pediatric CKD Patients in Relation to Hyperuricemia and its Treatment
}

\author{
IHAB Z. EL-HAKIM, M.D.; EMAN M. ELSAYED, M.D.; MOHAMED N. EL-SHARAWI, M.D. and \\ AYAAT A. MASRY, M.Sc.
}

The Department of Pediatrics, Faculty of Medicine, Ain Shams University

\begin{abstract}
Background: The prevalence of hyperuricemia in CKD pediatric patients increases in parallel with the estimated glomerular filtration rate (eGFR) decline, which is present in $40 \%$ to $60 \%$ of patients with CKD stages 1 to 3 and in $70 \%$ of patients with CKD stage 4, in this study, we aimed to study the prevalence of hyperuricemia among CKD paediatric patients in stages 2,3,4 and its effect on cardiac indices, and effect of allopurinol treatment on cardiac indices.
\end{abstract}

Aim of Study: The Prevalence of hyperuricemia among CKD paediatric patients and its effect on cardiac indices. The impact of treatment with allopurinol for 6 months in hyperuricemic CKD pediatric patients on cardiac indices.

Patients and Methods: A prospective cohort study was conducted on 78 CKD pediatric patients in stages 2,3,4 recruited from nephrology clinic Ain Shams University Hospital during the period from December 2019 to February 2020.

Results: There were highly statistically significant negative correlation between serum uric acid level and GFR with $p$ value $>0.001$ and there were a highly significant relation between the level of uric acid and CKD stage with $p$-value $>0.001$, and there were a highly significant diffirane in cardiac indices before and after the treatment. There was a highly significant relationship between the level of uric acid before and after allopurinol treatment which showing the effectiveness of the drug for decreasing the uric acid level in the blood and it's effect on the kidney and cardiovascular systeme.

Conclusion: 6 months administration of allopurinol treatment in hyperuriamic CKD pediatric patients in stages 2,3,4 resulted in improving the laboratory data of (uric acid level, serum creatinine, GFR) and showing a significant effect on cardiac indices (LV structure, systolic and diastolic function).

Key Words: Cardiac affection - Pediatric CKD patients Hyperuricemia - Treatment.

\section{Introduction}

URIC acid has long been considered an inert end product of purine catabolism; however, chronic hyperuricemia, causing deposition of urate crystals

Correspondence to: Dr. Ihab Z. El-Hakim, The Department of Pediatrics, Faculty of Medicine, Ain Shams University in the body, and considered as an independent risk factor for the development of chronic kidney disease (CKD) and cardiovascular diseases [1] .

Hyperuricemia occurs when the serum uric acid exceeds the normal level which is different according to age and changed from male to female above age of 15 years old, at this point starts to crystalize within the human body [2] .

High uric acid might be a predictor for occurrence of cardiac changes, in the form of structural remodelling, through increase in oxygen free radicals' production and its reactive metabolites may contribute to cardiac pathological consequences such as thrombosis, inflammation, and tissue remodelling in the form of cardio hypertrophy, interstitial fibrosis, and impaired diastolic relaxation [3].

Hyperuricemia has been associated also with left atrial remodelling, leading to an increase its size, which might be a risk factor to atrial fibrillation [4].

Xanthine oxidase inhibitors (XOIs) still remain the first line of treatment as recommended by all guidelines of gout. Among these, allopurinol is the first-line agent for treatment of hyperuricemia [5]

\section{Aim of the work:}

The aim of this study is to study affection of cardiac indices in CKD pediatric patients with hyperuricemia before and after the treatment with allopurinol for 6 months.

\section{Subjects and Methods}

Type of study: A pilot prospective cohort study.

Study setting: Outpatient pediatric nephrology clinic, Ain Shams University Hospitals. 
Study duration: Six months (as the metaanalysis studies reported improvement in kidney functions within six months after receiving allopurinol in adult CKD patients).

Study design: The study was conducted on (78) patients with chronic kidney disease in stage $2,3,4$, recruited during the period from December (2019) to February (2020) by consecutive sampling.

The patients classified into 2 groups according to their uric acid level:

Group (1): With normal uric acid level: This group included (53) CKD pediatric patients in stages 2,3,4. (19) of them were females and (34) were males, patients ages ranged from one year to 15 years old with median age 6 years. (22) patients of them in stage $2,(30)$ patients in stage 3 , and only one patient in stage 4 .

Group (2): With hyperuricemia: This group included (25) CKD pediatric patients in stages $2,3,4$. (7) of them were females, (18) were males, patients ages ranged from one year to 12 years old with median age 5 years. (17) patients of them in stage 3 , and (8) patients in stage 4 , there is no patients in stage 2 .

Inclusion criteria: Predialysis CKD stages 2,3,4.

Exclusion criteria: Any congenital cardiac anomalies or cardiac diseases. Nephrocalcinosis, gout, or any disease that interfere uric acid level.

\section{Study procedure:}

The 2 groups enrolled in the study will subjected to the following: History taking with special emphasis on the: Patients variables: Name, age, gender, originally affected systems and if there is any history of drug intake. History of any disease that might interfere with the uric acid level in the body as gout or nephrocalcinosis. History of any cardiac diseases or congenital cardiac anomalies.

Clinical examination: Complete physical examination before the study includes, vital data, weight, height, any signs of yellow complexion, paleness, edema, puffiness of eye lids, ecchymotic patches or pitcue on the skin or any respiratory signs (tachypnea, shallow rapid breath). In addition to examination for signs of including (swollen, red, tender joint especially big toe).

Ethical consideration: An informed verbal consent obtained from the care giver for each infant before enrolment into the study.

\section{Laboratory investigations:}

All patients in the study at the start of the study evaluated with: Serum uric acid (done by Uricase method, with Beckman coulter AU analyser). Serum creatinine. Estimation of GFR (by revised bedside Schwartz formula).

Only patients of group (2) (the hyperuricemic patients) were subjected to the following:

Allopurinol therapy: All the patients in group (2) received allopurinol treatment with dose of $10 \mathrm{mg} / \mathrm{kg} /$ day for six months [trade name is zyloric $100 \mathrm{mg} / 300 \mathrm{mg}$ tablets, made in England, GlaxosmithKline company (GSK)].

Transthoracic echocardiography: Echocardiography examination performed for all cases of group (2) hyperuricemic patients in supine position using (Vivid t8 expert, GE, made in china) according to age of the patient will be examined before and after receiving of allopurinol therapy.

Assessment included: All hyperuricemic patients evaluated with two dimensional and tissue coloured Doppler echocardiography with multiple subxiphoid and pericardial windows. Left ventricle and right ventricle myocardial performance index (MPI) were assessed by dividing the sum of isovolumic contraction and relaxation times by the ejection time and standard formula. MPI is inversely related to myocardial function and an increase in MPI indicates impaired global myocardial function. The procedure done with 2 operators but each patient done with the same operator before and after.

\section{ECHO parameters:}

Cardiac structure: It is represented with left ventricular mass index (LVMI) which is calculated with using the devereux formula: [6]

$\mathrm{LVM}=0.8^{*}(\mathrm{LVEDD}+\mathrm{PWT}+\mathrm{LVSDT}) 3-(\mathrm{LVEDD}) 3+0.6 \mathrm{~g}$

Where LVEDD is left ventricular diameter in end diastole, PWT is posterior wall thickness in diastole and IVSDT is interventricular septum thickness in end diastole.

LVM index (LVMI) was calculated by dividing LVM by height $(\mathrm{m})^{2}$ and expressed in $\mathrm{g} / \mathrm{m}^{2}$.

Left ventricular hypertrophy $(\mathrm{LVH})$ was defined as the LVMI $<38 \mathrm{~g} / \mathrm{m}^{2}$ ( $<95$ th percentile of pediatric population).

The relative wall thickness (RWT) was calculated as an index of the LV geometry pattern.

\section{$L V$ systolic function:}

The systolic function of left ventricle evaluated by the calculation of ejection fraction (EF) and fractional shortening (FS):

EF: (End diastolic diameter - End systolic volume)/end diastolic diameter $* 100$. 
FS: (End diastolic volume End systolic volume)/end diastolic volume $* 100$.

\section{LV diastolic function:}

Assessed by determining maximal early ( $\mathrm{E}$ wave) and late (A wave) diastolic flow velocities and $\mathrm{E} / \mathrm{A}$ ratio.

TDI: LV myocardial tissue imaging studies were performed during contractions and relaxation of LV to assess the sample velocity at the lateral margins of mitral annulus.

All parameters were measured during three consecutive cardiac cycles, with using their mean values [7].

The peak systolic velocity was ( $\mathrm{s}^{`}$ wave), the early ( $E^{`}$ wave) and late (A`wave) diastolic septal mitral annular peak velocities were recorded.

Early diastole was assessed using the index of $\mathrm{LV}$ relaxation $\left(\mathrm{E}^{\prime}\right)$. Late diastole was evaluated using the index of LV compliance (LV filling pressure. E/E`ratio).

\section{Myocardial performance index "Tei index":}

It is an index that incorporates both systolic and diastolic time intervals in expressing global systolic and diastolic ventricular function. Systolic dysfunction prolongs prejection (isovolumic contraction time, IVCT) and a shortening of the ejection time (ET). Both systolic and diastolic dysfunction result in abnormality in myocardial relaxation which prolongs the relaxation period (isovolumic relaxation time, IVRT) (Poulsen et al., 2000).

At the end of 6 months period of allopurinol therapy for group (2) hyperuricemic patients reevaluation done by: ECHO parameters. Laboratory investigations: Included (serum uric acid level, serum creatinine, Estimated GFR).

\section{Results}

The majority $(67.9 \%)$ the patients were with normal uric acid, while only (32.1\%) of the patients have high uric acid level.

Table (1): Comparison between CKD stage in 2 groups.

\begin{tabular}{cllll}
\hline $\begin{array}{l}\text { Before } \\
\text { CKD stage }\end{array}$ & $\begin{array}{c}\text { Normal } \\
(\mathrm{n}=53)\end{array}$ & $\begin{array}{c}\text { Hyper } \\
(\mathrm{n}=25)\end{array}$ & $\begin{array}{c}\text { Chi-square } \\
\text { test }\end{array}$ & $\begin{array}{c}p^{-} \\
\text {value }\end{array}$ \\
\hline II & $22(41.5 \%)$ & $0(0 \%)$ & 24.094 & $<0.001 * *$ \\
III & $30(56.6 \%)$ & $17(68 \%)$ & & \\
IV & $1(1.9 \%)$ & $8(32 \%)$ & & \\
\hline
\end{tabular}

Using: $\mathrm{x}^{2}$ : Chi-square test. $* * * p$-value $<0.001 \mathrm{HS}$.
This table shows highly statistically significant difference between normal and hyper uric acid according to CKD stage.

Table (2): The effect of treatment on cardiac indices in hyperurecimic patients.

\begin{tabular}{|c|c|c|c|c|}
\hline Cardiac indices & $\begin{array}{l}\text { Before } \\
(\mathrm{n}=25)\end{array}$ & $\begin{array}{c}\text { After } \\
(\mathrm{n}=25)\end{array}$ & Test & $\underset{\text { value }}{p-}$ \\
\hline $\begin{array}{l}\text { LVmass: } \\
\quad \text { Range } \\
\text { Mean } \pm \text { SD } \\
\text { Median (IQR) }\end{array}$ & $\begin{array}{l}20.5-50.3 \\
30.58 \pm 7 \\
29.50\end{array}$ & $\begin{array}{l}20-44 \\
29.15 \pm 5 \\
29\end{array}$ & $\mathrm{z}=2.637$ & $0.008 *$ \\
\hline $\begin{array}{l}L V E F: \\
\quad \text { Range } \\
\text { Mean } \pm \text { SD } \\
\text { Median (IQR) }\end{array}$ & $\begin{array}{l}66-85 \\
74.42 \pm 6 \\
74\end{array}$ & $\begin{array}{l}67-87 \\
77.63 \pm 5 \\
78\end{array}$ & $t=-4.272$ & $<0.001 * *$ \\
\hline $\begin{array}{l}F S: \\
\quad \text { Range } \\
\text { Mean } \pm \text { SD } \\
\text { Median (IQR) }\end{array}$ & $\begin{array}{l}33-47 \\
40.16 \pm 4 \\
41\end{array}$ & $\begin{array}{l}34-47 \\
40.05 \pm 3 \\
40\end{array}$ & $t=0.139$ & 0.891 \\
\hline $\begin{array}{l}E: \\
\quad \text { Range } \\
\text { Mean } \pm \text { SD } \\
\\
\text { Median (IQR) }\end{array}$ & $\begin{array}{l}10-18 \\
15.32 \pm 2 . \\
15.70\end{array}$ & $\begin{array}{l}9.8-20.5 \\
16.36 \pm 2 . \\
16.6\end{array}$ & $t=-6.531$ & $<0.001 * *$ \\
\hline $\begin{array}{l}\text { A: } \\
\quad \text { Range } \\
\text { Mean } \pm \text { SD } \\
\text { Median (IQR) }\end{array}$ & $\begin{array}{l}6-7 \\
6.66 \pm 0.5 \\
6.8\end{array}$ & $\begin{array}{l}5.9-7.5 \\
6.71 \pm 0.5 \\
6.9\end{array}$ & $z=2.085$ & $0.037 *$ \\
\hline $\begin{array}{l}S: \\
\quad \text { Range } \\
\text { Mean } \pm \text { SD } \\
\text { Median (IQR) }\end{array}$ & $\begin{array}{l}6-13 \\
8.82 \pm 1.5 \\
8.90\end{array}$ & $\begin{array}{l}6-13 \\
8.89 \pm 1.5 \\
9\end{array}$ & $t=-2.535$ & $0.021 *$ \\
\hline $\begin{array}{l}E / E: \\
\quad \text { Range } \\
\text { Mean } \pm \text { SD } \\
\text { Median (IQR) }\end{array}$ & $\begin{array}{l}5-8.6 \\
6.60 \pm 0.9 \\
6.50\end{array}$ & $\begin{array}{l}4.8-8.5 \\
6.23 \pm 0.7 \\
6.2\end{array}$ & $z=2.093$ & $0.036^{*}$ \\
\hline $\begin{array}{l}E / A: \\
\quad \text { Range } \\
\text { Mean } \pm \text { SD } \\
\text { Median (IQR) }\end{array}$ & $\begin{array}{l}1.3-2.1 \\
1.70 \pm 0.2 \\
1.78\end{array}$ & $\begin{array}{l}1.12-1.8 \\
1.51 \pm 0.2 \\
1.5\end{array}$ & $t=6.093$ & $<0.001 * *$ \\
\hline $\begin{array}{l}\text { Tei index: } \\
\text { Range } \\
\text { Mean } \pm \text { SD } \\
\text { Median (IQR) }\end{array}$ & $\begin{array}{l}0.32-0.9 \\
0.60 \pm 0.1 \\
0.52\end{array}$ & $\begin{array}{l}0.3-0.89 \\
0.52 \pm 0.1 \\
0.50\end{array}$ & $\mathrm{z}=3.824$ & $<0.001 * *$ \\
\hline
\end{tabular}

Using: $t$-Paired Sample $t$-test. z-Wilcoxon z-test

$p$-value $>0.05 \mathrm{NS} . \quad * x$-value $<0.05 \mathrm{~S}$. $* * * p$-value $<0.001 \mathrm{HS}$.

From analysis of this data showing statistically significant difference between before treatment and after treatment according to cardiac indices in hyper uric patients, except for FS.

Table (3): Comparison between 2 groups in calculated GFR.

\begin{tabular}{lllll}
\hline GFR & $\begin{array}{l}\text { Before } \\
(\mathrm{n}=25)\end{array}$ & $\begin{array}{c}\text { After } \\
(\mathrm{n}=25)\end{array}$ & $t$-test & $\begin{array}{c}p \text { - } \\
\text { value }\end{array}$ \\
\hline Range & $18-47$ & $21-60$ & -3.390 & $0.003 *$ \\
Mean士SD & $31.79 \pm 7.69$ & $35.42 \pm 9.74$ & & \\
Median (IQR) & $32(11)$ & $33(13)$ & & \\
\hline Using: $t$-Paired Sample $t$-test. & $* * p$-value $<0.05 \mathrm{~S}$.
\end{tabular}


So, the data analysis from the previous table shows statistically significant difference between before treatment and after treatment according to GFR in hyper uric patients.

Table (4): S.uric acid level in variant CKD Stages.

\begin{tabular}{llll}
\hline \multirow{2}{*}{ Uric Acid } & \multicolumn{3}{c}{ CKD stage } \\
\cline { 2 - 4 } & \multicolumn{1}{c}{2} & \multicolumn{1}{c}{3} & \multicolumn{1}{c}{4} \\
\hline Range & $1.3-4.3$ & $1.5-12$ & $3.8-14$ \\
Mean \pm SD & $2.56 \pm 1.01$ & $5.69 \pm 2.49$ & $7.90 \pm 2.94$ \\
Median (IQR) & 2.35 & 5.20 & 7 \\
\hline
\end{tabular}

This table showing the relation of serum uric acid level and CKD stage.

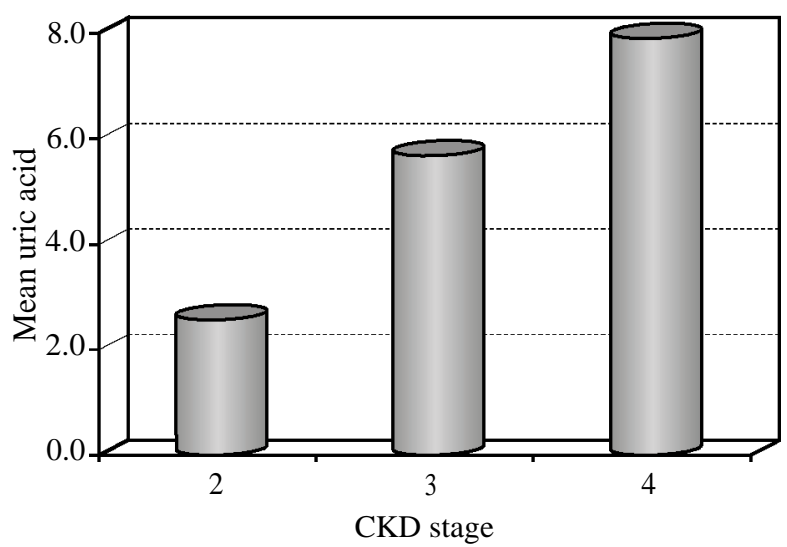

Fig. (1): Bar chart relation between uric acid and CKD stage.

This figure showing positive correlation between serum uric acid level and CKD stage.

Table (5): Comparison between CKD stage before and after.

\begin{tabular}{|c|c|c|c|}
\hline \multirow{2}{*}{$\begin{array}{l}\text { CKD stage } \\
\text { (before ttt) }\end{array}$} & \multicolumn{3}{|c|}{ CKD stage (after $\mathrm{ttt})$} \\
\hline & $2(n=1)$ & $3(n=13)$ & $4(n=5)$ \\
\hline $3(n=13)$ & $1(5.3 \%)$ & $10(52.6 \%)$ & $2(10.5 \%)$ \\
\hline $4(n=6)$ & $0(0 \%)$ & $3 \quad(15.8 \%)$ & $3(15.8 \%)$ \\
\hline
\end{tabular}

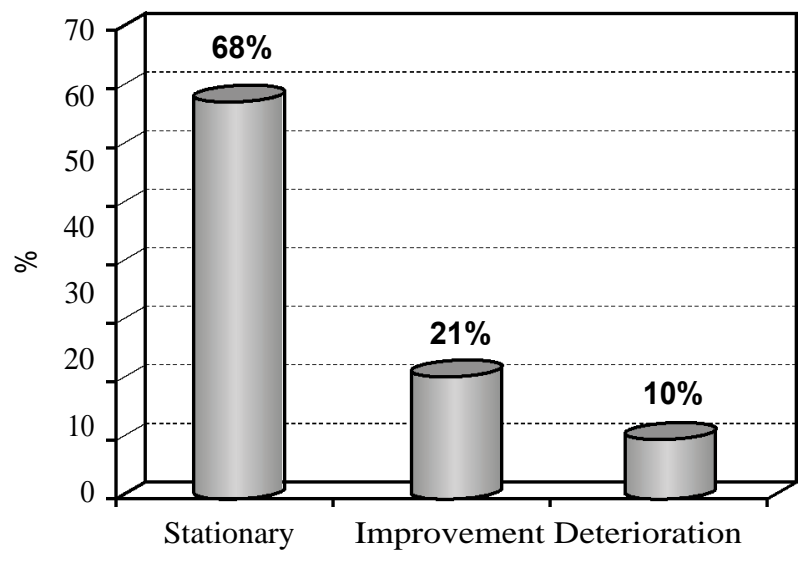

Fig. (2): Effect of treatment on CKD stage.
This figure showing that $21 \%$ of the patients showing improving in CKD stage after treatment, only $10 \%$ showing deterioration in CKD stage, and $68 \%$ are stationary.

\section{Discussion}

Recent studies have implicated hyperuricemia as a risk factor for cardiovascular diseases through endothelial dysfunction which is the early manifestation of vascular injury and contributes to the development of atherosclerotic cardiovascular disease. So, it was hypothesized that lowering uric acid in subjects with hyperuricemia with allopurinol treatment might improve endothelial dysfunction, estimated GFR (eGFR), and cardiac geometry, diastolic and systolic functions of the heart [8]

Hyperuricemia is defined as a laboratory abnormality in uric acid levels equal [ $(3.6-4.5 \mathrm{mg} / \mathrm{dl})$ +/-2] which changes in children and adolescents during development. So, age and sex-related reference values for serum uric acid should be considered. Generally, the hyperuricemia in CKD pediatric patients increases in parallel with the estimated glomerular filtration rate (eGFR) decline. It is present in $40 \%$ to $60 \%$ of patients with CKD stages 1 to 3 and in $70 \%$ of patients with CKD stage 4 [9].

In most of the studies reported, uric acid has shown to affect the kidney function through the effect on serum creatinine and eGFR so, the prevalence of hyperuricemia increases in advanced CKD stages. (Corry et al., 2008).

The aim of this study is to study affection of cardiac indices in CKD pediatric patients with hyperuricemia before and after the treatment with allopurinol for 6 months.

This is a pilot study as it is the first study to correlate between the effect of hyperuricemia on serum creatinine, eGFR, and cardiac indices (cardiac geometry, systolic and diastolic function) and the effect of decreasing of serum uric acid with allopurinol treatment for 6 months through comparing the values of serum creatinine, eGFR, and cardiac indices before and after treatment.

The study included 78 CKD pediatric patients in stages 2,3,4 who followed-up in The Pediatric Nephrology Clinic Ain Shams University Hospital during the period from December 2019 to February 2020. (25) of them were hyperuricemic, only (19) patients of them continued the study and (6) patients were missed during follow-up, (14) were males $(73.7 \%)$, and (5) patients were females $(26.3 \%)$. 
Their ages ranged from 1 year to 15 years with median age (6) years. The age stratification of our subjects was ranging from 1-12 years old.

The present study, showed that lowering serum uric acid had a positive effect regarding improvement of GFR and CKD staging through decreasing level of serum uric acid. This could be attributed to stoppage of crystallization of uric acid and formation of urate deposits in the body and the vascular endothelium of vessel walls and renal parenchyma [10].

Before receiving the treatment, $28.2 \%$ of hyperuricemic patients were in CKD stage 2, while $60.3 \%$ in stage 3 , and $11.5 \%$ of them in stage 4 .

But after 6 months treatment, $21 \%$ of the patients showing improvement in CKD stage, only $10 \%$ showing deterioration, and $68 \%$ are stationary which consider an improvement as the chronic kidney disease is progressive disease in nature.

Regarding laboratory data, there was a high statistically significant difference between before and after the treatment in s. uric acid, s. creatinine, eGFR with $(p$-value $=>0.001)$. which explained the possible effect of allopurinol treatment as regarding kidney function measurements.

There was also a high significant correlation between serum uric acid level and CKD stage with ( $p$-value >0.001), and highly significant difference between GFR and serum uric acid with ( $p$-value $>0.001$ ), comparing with non-statistically significant results regarding to (age, sex, weight, height), and also there was no statistically significant difference regarding the relationship between uric acid level and the type of kidney disease.

Similar to the positive effect of allopurinol in the study of Kanbay et al. [8] to evaluating effect of allopurinol on the glomerular filtration rate of patients with chronic kidney disease showed that allopurinol treatment resulted in a decreasing serum uric acid, a decrease in systolic and diastolic BP, a decrease in hsCRP, and an increase in eGFR compared with the baseline values ( $p<0.05$ for all), but this study done in adults CKD patients above 40 years old.

\section{Regarding cardiac parameters:}

Cardiac structure:In the present study, the LV mass index (LVMI) showing significant difference with $(p$-value $=0.008)$.

$L V$ systolic function: Left ventricular ejection fraction (LVEF) showing significant difference between before and after treatment with ( $p$-value $=>0.001$ ).

But there is no statistically significant difference in FS in the studied group before and after treatment which could be explained with the short period of treatment for only 6 months and could be showing change with increasing the period of treatment.

LV diastolic function, Conventional PWD (Pulsed wave Doppler) has been widely used to assess LV diastolic function and, it showing, a decrease in the E/A ratio which is the index of LV relaxation and indicates diastolic dysfunction, it was significant for early transmittal flow wave $\left(E^{\prime}\right)$ wave with ( $p$-value $\left.=>0.001\right)$ and for late flow wave with atrial contraction (A) wave velocity with $(p$-value $=0.037)$, regarding $\left(\mathrm{S}^{\prime}\right)$ wave velocity it was significant with $(p$-value $=0.021)$.

The E/E ratio, and $\mathrm{E} / \mathrm{A}$ ratio showing significant difference with $\left(p\right.$-value for $\left.\mathrm{E} / \mathrm{E}^{`}=0.036\right)$ and ( $p$-value for E/A ratio >0.001) as regarding to Tei index was highly significant diffirance with ( $p$ value $=>0.001$ ).

Mitsnefes et al. [11], which study the affection of CKD on LV function in pediatric CKD patients determined low $\mathrm{E} / \mathrm{A}$ ratio but there is another studies comparing the predialysis CKD pediatric patients with healthy children, showing that the E/A ratio were similar to the healthy children not affected with renal function, in our study we studied the E/A ratio in hyperuricemic predialysis CKD patients which improved significantly after treatment, these controversial results related to E/A ratio in CKD patients could be explained due to influencing of PWD with several factors as preload and left atrial pressure.

(E') early diastolic myocardial peak velocity by TDI is a relatively independent index of LV relaxation and used to assess LV early diastole, in our study we determined significantly improvement with treatment, in Mitsnefes et al. [11] the E` was relatively low which indicating diastolic dysfunction.

$\mathrm{E} / \mathrm{E}^{\prime}$ ratio by the combination of transmittal flow velocity with annular velocity, it considered another index of diastolic function, evaluates LV myocardial compliance at end diastole particularly in patients with preserved systolic function, increased E/E` ratio point out elevated filling pressures and therefore, impaired diastolic function [12].

Mitsnefes et al. [11], found significantly higher E/E` ratio in predialysis, comparing with our study 
it was showing significantly high $\mathrm{E} / \mathrm{E}^{`}$ ratio also after treatment.

In adults, studies confirmed that hyperuricemia is associated with more rapid reduction in kidney function, which is still not confirmed in children yet [13]

So, if uric acid level predicts faster deterioration in glomerular filtration rate (GFR) in children with CKD as in adult, the urate-lowering therapy to CKD will be added to treatment protocols for children with predialysis CKD stages [13]

\section{Conclusions:}

6 months administration of allopurinol treatment in hyperurcmic CKD pediatric patients in stages 2,3,4 with uric acid exceeding the normal level resulted in improving the laboratory data of (uric acid level, serum creatinine, GFR) and showing a significant effect on cardiac indices (LV structure, systolic and diastolic function).

\section{References}

1- JOHNSON R., BAKRIS G., BORGHI C., et al.: Hyperuricemia, Acute and Chronic Kidney Disease. Am. J. Kidney Dis., 30 (8): 851-865, 2018.

2- YAMANAKA H.: Japanese Guideline for the Management of Hyperuricemia and Gout: Second Edition, Nucleosides, Nucleotides and Nucleic Acids, 30 (12): 1018-1029, 2011.

3- DUDLEY S.C., HOCH N.E., McCANN L.A., et al.: Atrial fibrillation increases production of superoxide by the left atrium and left atrial appendage: Role of the NADPH and xanthine oxidases. Circulation, 112: 1266-73, 2005.

4- CHO T.F., HUNG C.L., CHEN S.J., et al.: The association between hyperuricemia, left atrial size and new-onset atrial fibrillation. Int. J. Cardiol., 168: 4027-32, 2013.

5- KHANNA D., FITZGERALD J., KHANNA P., et al.:
American College of Rheumatology Guidelines for management of gout. Part 1: Systematic nonpharmacologic and pharmacologic therapeutic approaches to hyperuricemia. Arthritis Care Res. (Hoboken), 64: 1431-1446, 2012.

6- CHENGODE S.: Left ventricular global systolic function assessment by echocardiography. Ann. Card Anaesth., 19 (Supplement): p. S26-S34, 2016.

7- ISAAZ K.: What are we actually measuring by Doppler tissue imaging? J. Am. Coll. Cardiol, 36: 897-9, 2000.

8- KANBAY M., HUDDAM B., AZAK A., SOLAK Y., KADIOGLU G.K., KIRBAS I., et al.: A randomized study of allopurinol on endothelial function and estimated glomular filtration rate in asymptomatic hyperuricemic subjects with normal renal function. Clinical Journal of the American Society of Nephrology, 6 (8): 1887-1894, 2011.

9- CHONCHOL M., SHLIPAK M.G., KATZ R., SARNAK M.J., NEWMAN A.B., SISCOVICK D.S., et al.: Relationship of uric acid with progression of kidney disease. American Journal of Kidney Diseases, 50 (2): 239-47, 2007.

10- CORRY D.B., ESLAMI P., YAMAMOTO K., NYBY M.D., MAKINO H. and TUCK M.L.: Uric acid stimulates vascular smoothmuscle cell proliferation and oxidative stress via the vascular renin-angiotensin system. J. Hypertens, 26: 269-275, 2008.

11- MITSNEFES M.M., KIMBALL T.R., BORDER W.L., et al.: Abnormal cardiac function in children after renal transplantation. Am. J. Kidney Dis., 43: 721-726, 2004.

12- OMMEN S.R., NISHIMURA R.A., APPLETON C.P., et al.: Clinical utility of Doppler echocardiography and tissue Doppler imaging in the estimation of left ventricular filling pressures: A comparative simultaneous Dopplercatheterization study. Circulation, 102: 1788-1794, 2000.

13-MAZZALI M., KANELLIS J. and HAN L.: Hyperuricemia induces aprimary renal arteriolopathy in rats by a blood pressure-independent mechanism. Am. J. Physiol. Renal Physiol., 282 (6): F991-F997, 2002. 


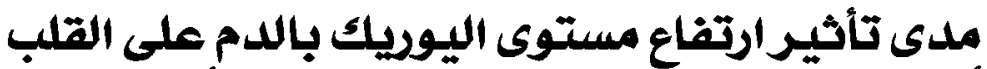

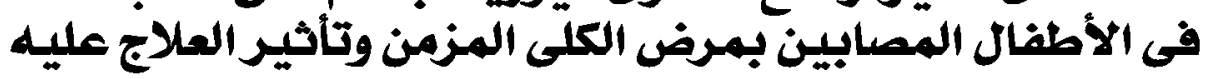

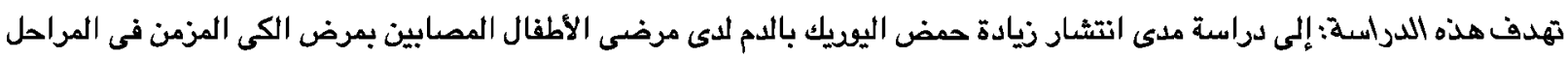

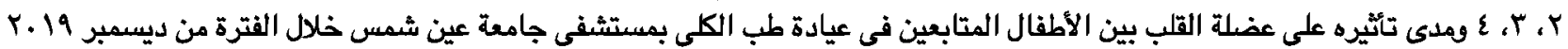

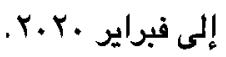

بالإضافة إلى تأثر عضلة القلب لدى هئلاء الأطفال الذين يعانون من زيادة حمض اليوريك بالدم قبل وبعد استخدام علاج الوبيوينول لمدة ب أشهر.

كانت الدراسة عبارة عن دراسة مستقبلية أجريت على ب مريضاً من مرضى الكلى المزمن فى المراحل r، ب،ع من المتابعين فى عيادة

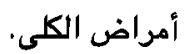
جميع الأطفال خضعوا إلى:

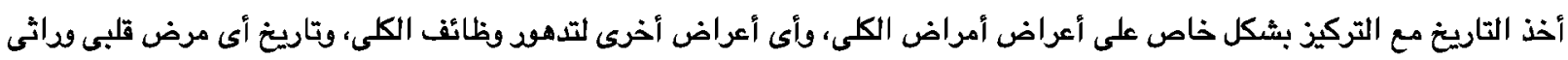

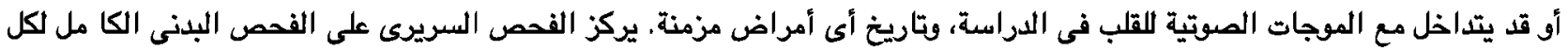

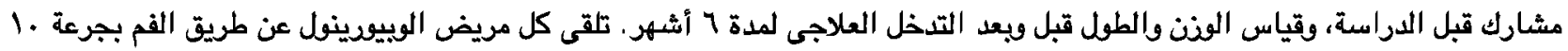

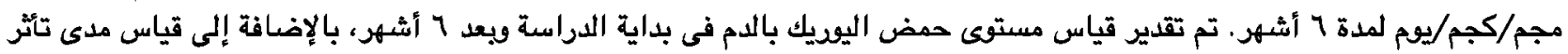

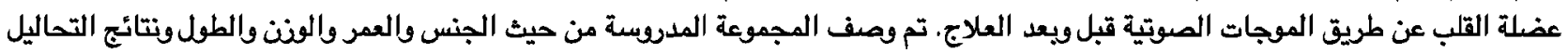

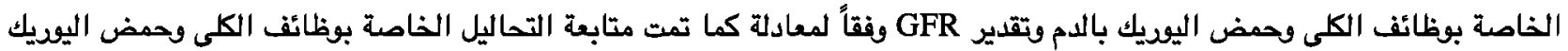

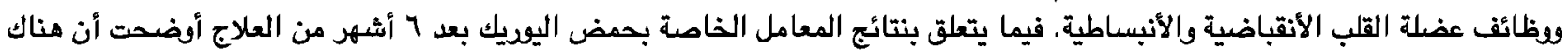

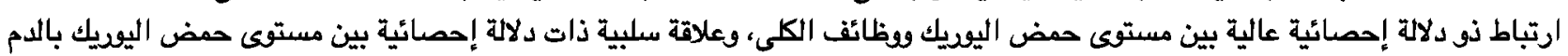

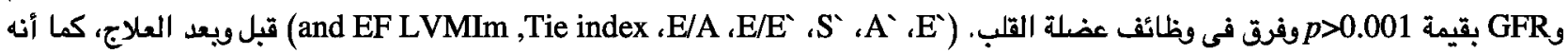
لم يكن هناك تأثير على قبل FS وبعد العلاج.

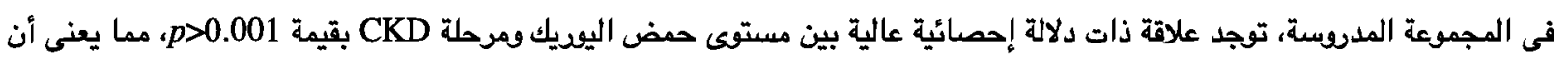

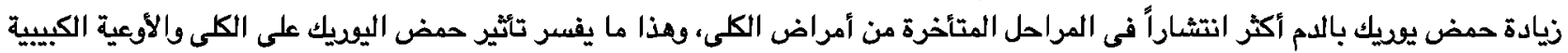

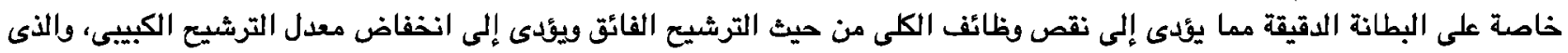

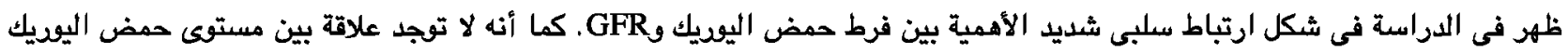

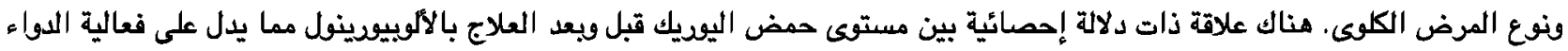
من حيث خفض مستوى حمض اليوريك بالدم وتأثيره على وظائف الكلى ووظائف عضلة القين القلب. 